\title{
SISTEM PENGENDALI PERINGATAN DINI KEBAKARAN PADA RUKO (Rumah Toko) MELALUI SMS (Short Mesasage Service)
}

\author{
Baihaqi Muqoddas*
}

\begin{abstract}
Abstrak: Allah SWT menyuruh kita untuk menjaga diri dan keluarga kita dan bersikap hati-hati serta waspada dari bahaya. Seperti dalam firmannya surat At-tahrim ayat 6 dan Al-Maidah ayat 92. Tindakan hati-hati dilakukan agar tidak terjadi sesuatu yang tidak diinginkan atau menjaga diri kita dari sesuatu yang dapat mencelakakan kita seperti kebakaran. Ruko atau rumah toko merupakan salah satu bangunan di perkotaan yang banyak kita dengar baik pada media cetak maupun elektronik sering mengalami kebakaran,baik oleh kelalaian yang disengaja atau yang tidak disengaja. Pada skripsi ini, penulis membuat suatu alat pengendali peringatan dini kebakaran pada ruko melalui Short Message Service (SMS). Alat ini dibuat dengan tujuan untuk mengetahui secara dini kebakaran. Kelebihan dari sistem ini adalah dapat memberikan informasi kebakaran kepada pemilik ruko berupa sms. Masukan dari sistem ini adalah sensor suhu yang menggunakan LM35 dan dikuatkan oleh op-amp yang dikondisikan untuk mendapatkan perubahan tiap skala derajat celcius. Selanjutnya masukan analog ini akan masuk ke ADC PCF8591 untuk mengubah sinyal analog dari sensor suhu kedalam bentuk digital. Sedangkan keluarna dari ADC akan masuk dan diolah oleh Mikrokontroler AT89S8252. Sistem ini akan mengirim sms bioa suhu melebihi batas yang ditentukan dan sistem akan menyalakan buzzer dan pompa. Dengan adanya alat ini diharapkan kita dapat mencegah bahaya kebakaran yang lebih besar, karena telah diketahui sejak dini.
\end{abstract}

Kata kunci: Pengendali, Peringatan dini, Kebakaran, SMS

\section{PENDAHULUAN}

Saat ini sistem keamanan dan keselamatan dalam suatu bangunan atau gedung adalah hal yang sangat penting. Salah satu faktor keamanan dan keselamatan yang perlu diperhatikan adalah masalah kebakaran. Kebakaran merupakan musibah yang disebabkan oleh api dan salah satu musibah yang ditakuti oleh banyak kalangan masyarakat. Karena apabila tidak diketahui secara dini, maka kebakaran akan semakin sulit diatasi, sebab api akan cepat membesar dan menyebar sehingga sulit dipadamkan. Karena kontruksi bangunan diperkotaan yang padat dan posisi bangunannya yang saling berdekatan akan memudahkan api cepat menjalar. Hal ini akan mengakibatkan kerugian materi yang cukup besar serta dapat juga menyebabkan korban jiwa.

Dari permasalahan di atas dibuat suatu alat pengendali peringatan dini kebakaran pada ruko atau rumah toko dengan memanfaatkan teknologi informasi pada handphone (HP) yaitu SMS dan mikrokontroler sebagai komponen pengendali atau pengontrolnya. SMS bertugas menginformasikan jika terjadi kenaikan suhu yang tidak wajar pada ruko atau rumah toko kepada pemiliknya sendiri-sendiri, sehingga kemungkinan terjadinya kebakaran dapat diatasi supaya pemilik ruko tidak mengalami kerugian atau kerugiannya dapat dikurangi. Alat ini dibuat untuk menginformasikan suhu yang tidak wajar pada beberapa pemilik ruko yang letaknya berdekatan sesuai dengan suhu pada rukonya masingmasing melalui SMS.

\section{KAJIAN TEORI Sensor Suhu}

Sensor suhu adalah alat yang digunakan untuk merubah besaran panas menjadi besaran listrik yang dapat dengan mudah dianalisis besarnya. Seri LM35 adalah IC sensor suhu yang presisi dimana tegangan keluarannya berbanding lurus dengan derajat suhu celcius (centrigade) sebesar $\pm 10 \mathrm{mV} /{ }^{\circ} \mathrm{C}$. LM 35 memiliki kelebihan-kelebihan sebagai

(*) Pemerhati Fisika 
berikut : dikalibrasi langsung dalam celcius; memiliki factor skala linear $+10.0 \mathrm{mV} /{ }^{\circ} \mathrm{C}$; memiliki ketepatan $0,5^{\circ} \mathrm{C}$ pada suhu $+25^{\circ} \mathrm{C}$; jangkauan maksimal suhu antara cocok untuk aplikasi jarak jauh; harga yang cukup murah; bekerja pada tegangan catu 4 sampai 30 Volt; memiliki arus drain kurang dari $60 \mathrm{uA}$; pemanasan sendiri yang lambat (low self-heating), $0,08^{\circ} \mathrm{C}$ di udara diam; ketidaklinearan hanya sekitar \pm 1 dan memiliki impedansi keluaran yang kecil, 0,1 W untuk beban $1 \mathrm{~mA}$.(Widodo,2005:119)

\section{Pengkondisi sinyal}

Sinyal-sinyal listrik yang dihasilkan oleh transduser harus dikonversi ke dalam bentuk yang dikenali oleh papan akuisisi data yang dipakai. Tugas pengkondisi sinyal yang sering dilakukan adalah penguatan (amplification). Penguat Operasional sering disingkat dengan sebutan Op_Amp merupakan komponen diskrit yang sekarang telah dikemas dalam bentuk IC monolitik, sehingga penggunaannya menjadi lebih mudah dan dengan biaya yang lebih murah.

\section{ADC (Analog to Digital Converter)}

Konverter analog ke dijital, dikenal luas dengan istilah ADC yang merupakan kependekan dari kata-kata asing analog to digital converter, banyak digunakan sebagai antarmuka antara rangkaian-rangkaian analog dengan mikrokontroler atau divais-divais digital lainnya.

\section{Mikrokontroler AT89S8252}

Mikrokontroler AT89S8252 merupakan pengembangan dari mikrokontroler standar MCS-51. Hal-hal yang terdapat pada penjelasan mikrokontroler MCS-51 juga berlaku untuk mikrokontroler AT89S8252. Secara sederhana mikrokontroler merupakan suatu IC yang didalamnya berisi CPU,ROM,RAM dan I/O. dengan adanya CPU tersebut maka mikrokontroler dapat melakukan proses berfikir berdasarkan program yang telah diberikan kepadanya. (Malik)

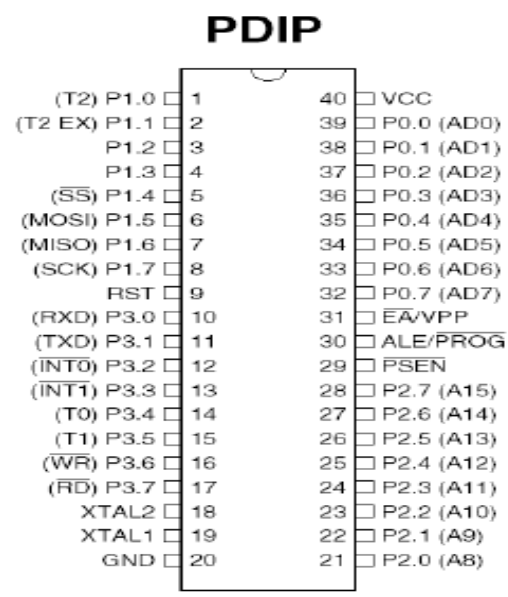

Gambar 1. Pin AT89S8252

\section{Relay}

Relai merupakan piranti elektromagnetis yang sering digunakan pada industri otomotif maupun elektronik. Relai berfungsi untuk menghubungkan atau memutuskan aliran listrik yang dikontrol dengan memberikan tegangan dan arus tertentu pada koilnya (widodo,2005:169) 


\section{Driver Relay}

Driver relay adalah rangkaian yang digunakan untuk menggerakkan relay. Driver yang dirancang menggunakan transistor. Seperti diketahui bahwa transisitor jenuh bagaikan saklar menutup sehingga menghantarkan arus (on), sedangkan transistor menyumbat bagaikan sakelar membuka (off). Transistor dalam keadaan jenuh akan mengantarkan arus sehingga relay akan bekerja.(sumisjokarto,1985:57)

\section{Perintah AT (AT COMMAND)}

Perintah AT (Hayes AT Command) digunakan untuk berkomunikasi dengan terminal (modem) melalui gerbang serial pada komputer. Dengan penggunaan perintah AT, dapat diketahui atau dibaca kondisi dari terminal, seperti mengetahui kondisi sinyal, kondisi baterai, mengirim pesan, membaca pesan, menambah item pada daftar telepon, dan sebagainya.

\section{PDU sebagai Bahasa SMS}

Pada prinsipnya terdapat dua mode untuk mengirim dan menerima SMS, yaitu mode text dan mode PDU (Protocol Data Unit). Sistem mode text tidak didukung oleh semua operator GSM maupun terminal yang ada. Pada mode text, pesan yang dikirim tidak dikonversi. Teks yang dikirim tetap dalam bentuk aslinya dengan panjang mencapai 160 (7 bit default alphabet) atau 140 (8 bit) karakter. Sesungguhnya mode text adalah hasil enkode yang direpresentasikan dalam format PDU. PDU mode adalah format message dalam heksadesimal octet dan semi-decimal octet dengan panjang mencapai 160 (7 bit default alphabet) atau 140 (8 bit) karakter. Data yang mengalir ke/dari SMS-Centre harus berbentuk PDU (Protocol Data Unit). PDU berisi bilangan-bilangan heksadesimal yang mencerminkan bahasa I/O. PDU terdiri atas beberapa header.

\section{LCD (Liquid crystal Display)}

LCD (Liquid crystal Display) merupakan suatu bentuk kristal cair yang akan berubah warnanya apabila dikenakan tegangan padanya. Tampilan berupa dot matrik $5 \times 7$, sehingga jenis huruf yang dapat ditampilkan akan lebih banyak dan lebih baik resolusinya jika dibandingkan dengan seven segment. Input yang diperlukan untuk mengendalikan modul ini berupa bus data yang termutipleks dengan bus alamat dan 3 bit sinyal kontrol. LCD yang dipakai adalah LCD dengan tipe M1632.

\section{Keypad 4x4}

Keypad 4x4 merupakan susunan 16 tombol membentuk keypad sebagai sarana input ke mikrokontroler, meskipun jumlah tombol ada 16 tapi hanya memerlukan 8 jalur port paralel. Tombol 0 sampai dengan 9 keypad berfungsi untuk memberikan nilai masukan batas suhu yang akan dikontrol. Keypad dihubungkan ke microcontroller AT89S8252 melalui port 3.

\section{METODE PENELITIAN}

Penelitian ini adalah rancang bangun alat dengan menguji coba alat sistem pengendali peringatan dini kebakaran pada ruko melalaui sms. Dan keluaran dari alat adalah SMS yang memberikan informasi bahaya kebakaran dan aktuator yang bekerja saat terjadi kebakaran.

\section{Alat dan Bahan}

1. Sensor suhu LM35

2. IC Penguat LM358 
3. ADC PCF8591

4. Mikrokontroler AT89S8252

5. Keypad

6. LCD M1632

7. Driver Relay

8. Buzzer

9. Pompa

10. Komponen elektronik pendukung

\section{Perencanaan Perangkat Keras}

Adapun perancangan alat yang digunakan dalam penelitian ini, seperti dalam diagram blok.

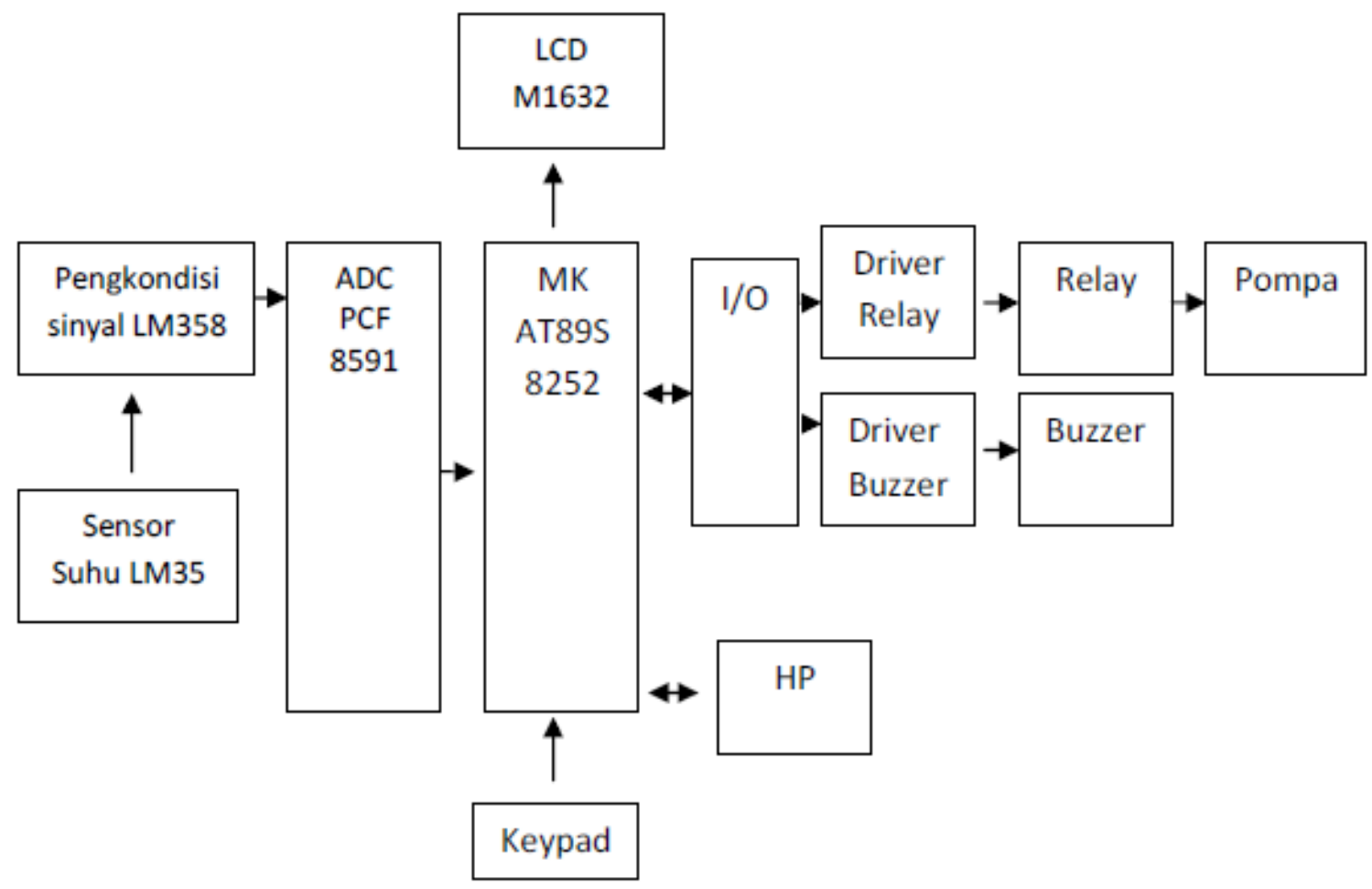

Gambar 2. Diagram blok sistem

Alat ini bekerja ketika panas yang diterima oleh sensor melebihi batas yang ditetapkan, setelah itu dikuatkan oleh IC LM358 sebagai penguat sinyal kemudian dikonversi ADC ke dalam bentuk digital untuk diolah oleh mikrokontroler. oleh mikrokontroler data-data tersebut diolah kemudian diteruskan dengan mengirimkan SMS ke nomor yang dituju. Driver relay yang digunakan adalah transistor 9012 dan 9013. Karena sensor yang dipakai ada 3 jadi nomor tujuan ada 3. Sedangkan buzzer dan pompa bekerja bila terjadi kebakaran. Alat ini dirancang untuk dipakai didalam ruangan.

\section{Perancangan Perangkat Lunak}

Perancangan perangkat lunak merupakan inti dari pembuatan alat ini, setelah perangkat keras selesai dibuat. Alat ini membutuhkan sebuah pengendali yang nantinya akan mengendalikan semua proses yang ada dalam seluruh sistem dan mengaturnya. Perangkat lunak ini nantinya akan dipakai pada mikrokontroler.

Sistem dirancang untuk mengontrol suhu, apabila suhu melebihi batas yang telah ditentukan maka sistem akan mengirm sms ke nomor HP yang telah dimasukkan sesuai 
dengan ruko masing-masing dan buzzer hidup setelah itu pompa akan menyala setelah buzzer.

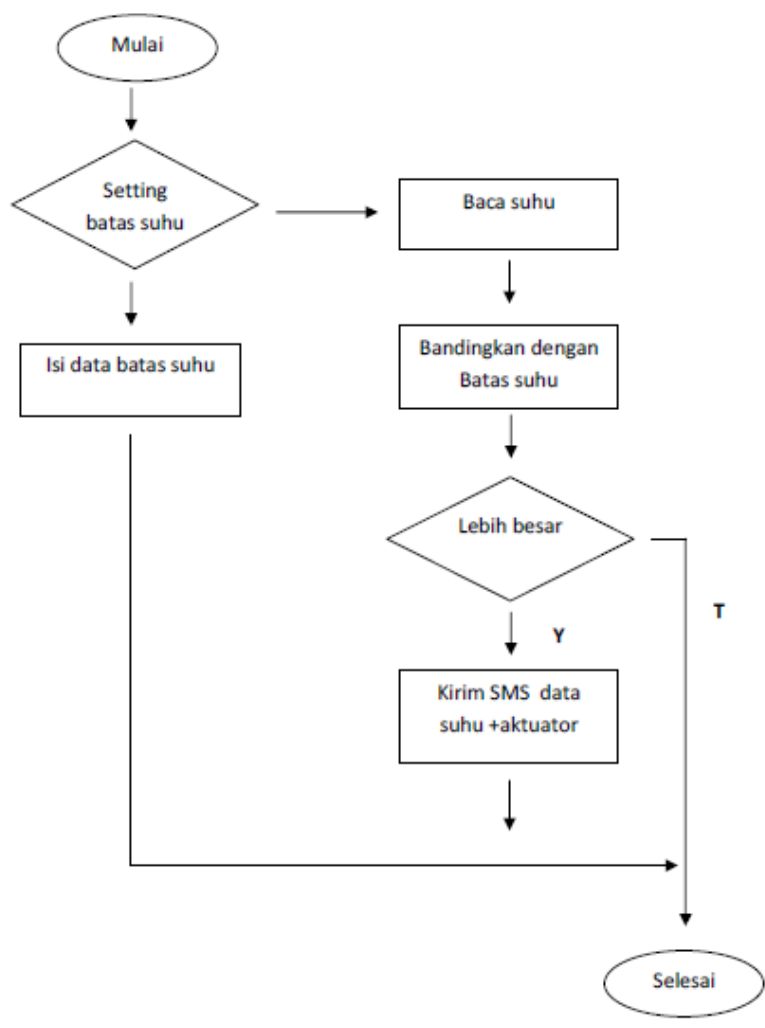

Gambar 3 Diagram alir perangkat lunak

\section{Pengujian Alat}

Pengujian dilakukan dengan tujuan untukmengetahui kinerja alat yang sudah dirancang, dapat bekerja sesuai dengan perencanaan atau belum. Pengujian dilakukan pada perangkat keras dan pengujian sistem secara keseluruhan.

\section{HASIL DAN PEMBAHASAN}

\section{Hasil pengujian rangkaian sensor suhu.}

Berikut data yang diperoleh pada saat pengujian rangkaian sensor suhu LM35.

Tabel 1. Hasil sensor suhu

\begin{tabular}{|c|c|c|c|c|}
\hline No & Suhu Aktual $\left({ }^{\circ} \mathrm{C}\right)$ & \multicolumn{2}{|c|}{ Vout(mV) } & \multirow{2}{*}{ Simpangan (\%) } \\
\cline { 3 - 4 } & & 250 & 254 & 1.60 \\
\hline 1 & 25,0 & 325 & 321 & 1.50 \\
\hline 2 & 32,5 & 400 & 405 & 1.25 \\
\hline 3 & 40,0 & 475 & 480 & 1.00 \\
\hline 4 & 47,5 & 550 & 555 & 0.80 \\
\hline 5 & 55,0 & 625 & 629 & 0.60 \\
\hline 6 & 62,5 & \multicolumn{3}{|l}{} \\
\hline \multicolumn{3}{|l}{} \\
\hline
\end{tabular}

\section{Hasil Pengujian Rangkaian Penguat Sinyal}

Berikut data yang diperoleh saat pengujian rangkaian penguat sinyal, IC yang dipakai adalah LM358 
Tabel 2 Hasil Pengujian Rangkaian Penguat Sinyal

\begin{tabular}{|c|c|c|c|c|}
\hline No & V input (mV) & \multicolumn{2}{|c|}{ Vout(mV) } & Simpangan (\%) \\
\cline { 3 - 4 } & & Perhitungan & Pengukuran & \\
\hline 1 & 75 & 294 & 289 & 1.7 \\
\hline 2 & 150 & 588 & 582 & 1.02 \\
\hline 3 & 225 & 882 & 889 & 0.93 \\
\hline 4 & 300 & 1176 & 1185 & 0.76 \\
\hline 5 & 375 & 1470 & 1460 & 0.68 \\
\hline \multicolumn{4}{|l}{} \\
\hline
\end{tabular}

\section{Hasil Pengujian Rangkaian ADC}

Data hasil konversi ADC untuk suhu terlihat pada tabel 4.3 dibawah ini:

Tabel 3. Hasil Konversi Suhu

\begin{tabular}{|c|c|c|c|c|}
\hline No & Suhu $\left({ }^{\circ} \mathrm{C}\right)$ & $\begin{array}{c}\mathrm{V}_{\text {out }} \text { Op Amp }=\mathrm{V}_{\text {in }} \\
\text { ADC }\end{array}$ & Konversi ADC & LCD \\
\hline 1 & 25,0 & 0,00 & 0 & 25,0 \\
\hline 2 & 32,0 & 294 & 15 & 32,5 \\
\hline 3 & 40,0 & 588 & 30 & 40,0 \\
\hline 4 & 47,5 & 882 & 45 & 47,5 \\
\hline 5 & 55,0 & 1176 & 60 & 55,0 \\
\hline 6 & 62,5 & 1470 & 75 & 62,5 \\
\hline
\end{tabular}

\section{Hasil Pengujian Rangkaian LCD} ditampilkan.

Hasil pengujian akan ditampilkan pada layar LCD sesuai dengan tulisan yang ingin

Tabel 4. Hasil Pengujian Rangkaian LCD

\begin{tabular}{|l|l|}
\hline Masukan & Keluaran LCD \\
\hline "Baihaqi Muqoddas" & Baihaqi Muqoddas \\
\hline "Nim : 04540025" & Nim : 04540025 \\
\hline
\end{tabular}

Dari komponen LCD yang dipakai untuk unit penampil dapat bekerja dengan baik yaitu dapat menampilkan karakter sesuai perencanaan.

\section{Hasil Pengujian Rangkaian Keypad}

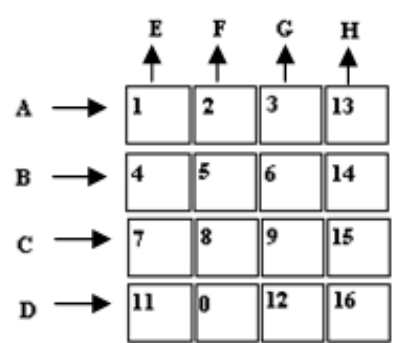

Gambar 4. Input dan output keypad 
Tabel 5. Hasil Pengujian Rangkaian Keypad

\begin{tabular}{|c|c|c|c|c|c|c|c|c|}
\hline \multicolumn{4}{|c|}{ Output } & \multicolumn{4}{|c|}{ Input } & \multirow{2}{*}{ karakter } \\
\hline $\mathrm{H}$ & $\mathrm{G}$ & $\mathrm{F}$ & $E$ & D & $\mathrm{C}$ & B & $\mathrm{A}$ & \\
\hline 1 & 1 & 1 & 0 & 1 & 1 & 1 & 0 & 1 \\
\hline 1 & 1 & 0 & 1 & 1 & 1 & 1 & 0 & 2 \\
\hline 1 & 0 & 1 & 1 & 1 & 1 & 1 & 0 & 3 \\
\hline 0 & 1 & 1 & 1 & 1 & 1 & 1 & 0 & 13 \\
\hline
\end{tabular}

\section{Hasil Pengujian Rangkaian Driver Relay}

Pengujian relay dan driver relay adalah untuk mengetahui apakan driver relay dapat berfungsi sesuai dengan perancangan. Adapun hasil pengujiannya adalah sebagai berikut:

Tabel 6. hasil pengujian rangkaian relay dan driver relay

\begin{tabular}{|c|c|c|c|c|}
\hline Logic & V Logic & V Driver & V Relay & Relay \\
\hline $\mathbf{0}$ & 0.02 & 0.5 & 11.56 & ON \\
\hline $\mathbf{1}$ & 4.95 & 11.84 & 0.2 & OFF \\
\hline
\end{tabular}

Tabel 7. Hasil Pengujian Rangkaian Driver Relay Buzzer

\begin{tabular}{|c|c|c|}
\hline No & Masukan & Buzzer \\
\hline 1 & 0 & Hidup \\
\hline 2 & 1 & Mati \\
\hline
\end{tabular}

Tabel 8. Hasil Pengujian Rangkaian Driver Relay Pompa

\begin{tabular}{|c|c|c|}
\hline No & Masukan & Pompa \\
\hline 1 & 0 & Hidup \\
\hline 2 & 1 & Mati \\
\hline
\end{tabular}

Rangkaian driver dan relay dapat bekerja dengan baik, saat mendapatkan tegangan maka relay akan menyambung dan bila tidak ada tegangan maka relay akan memutuskan saluran. Ini sesuai dengan perencanaan.

\section{Pembahasan rangkaian sensor suhu}

Berdasarkan data hasil pengujian pada tabel 4.1 didapatkan data suhu. Hasil pengukuran didapatkan dengan mengukur keluaran sensor dengan multimeter dan dibandingkan dengan nilai perhitungan. Dari perbandingan tersebut kita mendapatkan simpangan rata-rata dari sensor ini adalah sebesar $1.12 \%$. simpangan tertinggi yaitu pada saat suhu 25C dan simpangannya terus menurun saat suhunya naik hal ini dikarenakan pada pengukuran ini kita menggunakan multimeter dalam skala milivolt. Dalam skala milivolt multimeter yang digunakan memiliki ciri khas yaitu semakin tinggi tegangan yang diberikan maka nilai keluarannya semakin mendekati nilai kebenaran atau sesuai dengan perhitungan. 


\section{Pembahasan Rangkaian penguat sinyal}

Penguat sinyal dipakai karena tegangan keluaran dari sensor terlalu rendah dan harus dikuatkan agar sesuai dengan masukan yang dibutuhkan oleh ADC. Berdasarkan hasil pengujian pada tabel 2 didapatkan simpangan rata-rata dari rangkaian penguat sinyal ini adalah sebesar $1.01 \%$. dari hasil pengukuran diatas kita membandingkan antara pengukuran dengan perhitungan. Dari tabel diatas kita mendapatkan hasil bahwa semakin besar tegangan yang diberikan maka semakin kecil simpangannya. hal ini dikarenakan pada pengukuran ini kita menggunakan multimeter dalam skala milivolt. Dalam skala milivotl multimeter yang digunakan memiliki ciri khas yaitu semakin tinggi tegangan yang diberikan maka nilai keluarannya semakin mendekati nilai kebenaran atau sesuai dengan perhitungan.

\section{Pembahasan rangkaian ADC}

Berdasarkan hasil Pengujian rangkaian ADC pada Tabel 3 didapatkan hasil konversi diatas merupakan hasil keluaran penguat Op-Amp yang disesuaikan dengan range tegangan masukan analog ADC yaitu $0-5 \mathrm{~V}$, Selanjutnya data analog dari pengkondisi sinyal akan dikonversi oleh ADC menjadi bentuk data digital agar dapat diproses oleh mikrokontroller. Data ADC didapat dari hasil pembagian antara resolusi ADC dengan tegangan masukan ADC, Sedangkan Vin ADC adalah Vout Op-Amp : Resolusi ADC = $5 / 255=0,0196$

\section{Pembahasan rangkaian LCD}

Hasil yang didapatkan dari tabel adalah keluaran dari LCD yang ingin ditampilkan. Pada LCD ada 2 baris. Baris pertama pengujian yaitu menampilkan nama selanjutnya baris kedua menampilkan nim. Dan ini sesuai dengan program pengujian.

\section{Pembahasan rangkaian keypad}

Hasil pengujian rangkaian keypad pada tabel 5 menunjukkan apabila tidak ada penekanan tombol semua logika bernilai 1 baik input baris maupun output kolom. Saat ada penekanan tombol, misalnya tombol 1, maka input a berlogika 0 dan output e berlogika 0 juga, sehingga karakter yang dikeluarkan adalah tombol 1, begitu juga untuk karakter 2, input a berlogika 0 dan output $\mathrm{f}$ berlogika 0 dan berurutan seterusnya.

\section{Pembahasan driver relay}

Berdasarkan hasil pengujian driver relay pada tabel 6 didapatkan tegangan yang dikeluarkan oleh mikrokontroler sebesar 0 dan 5 volt. Namun dalam kenyataannya tegangan ini tidak bisa digunakan secara langsung untuk menggerakkan beban. Hal ini disebabkan karena arus yang mampu dilewatkan oleh kaki-kaki mikrokontroler sangat kecil. Untuk itu perlu dipasang piranti yang mampu menguatkan arus, sehingga dapat digunakan untuk menggerakkan beban. Piranti ini biasa disebut dengan driver.

\section{Pembahasan Perangkat Lunak}

Untuk dapat mengendalikan sistem pada alat ini, digunakan mikrokontroler AT89S8252. Bahasa program yang digunakan adalah bahasa assembler. Program ini bertujuan untuk memberikan informasi sms kepada nomor telepon seluler pemilik ruko yang telah dimasukkan di mikrokontroler AT89S8252.

Pertama kita memasang semua rangkaian sesuai dengan skema. Hp yang digunakan adalah tipe M35i. Pertama kali kita mensetting dulu batas suhu kemudian kita memasukkan nomor HP sesuai dengan pemilik Ruko masing-masing. Pada Sistem ini mikrokontroler terlebih dahulu mendeteksi keadaan sensor suhu setelah itu dikuatkan oleh 
penguat sinyal kemudian dikonversi oleh ADC yang akan dikirim ke Mikrokontroler. Pengendalian sistem secara keseluruhan berpusat pada mikrokontroler. Langkah-langkah atau alur jalannya kontrol yang dilakukan mikrokontroler sepenuhnya diatur oleh program utama mikrokontroler yang dalam hal ini menggunakan bahasa pemograman assembler.

Dalam program ini setelah suhu yang dideteksi oleh Mikrokontroler melebihi batas yang telah kita tentukan maka akan ada pengontrolan yang dilakukan oleh Mikrokontroler yakni dengan mengirim sms kepada pemilik Ruko yang suhunya dideteksi melebihi batas. Sms pertama adalah "Ruko 1 Bahaya" dan diikuti dengan hidupnya buzzer. Setelah beberapa detik suhunya berkurang maka mikrokontroler akan mengirim sms memberi informasi "Ruko 1 aman", bila suhunya terus naik sampai melebihi batas yang ditentukan maka mikrokontroler akan mengirim sms "semprot" yakni aktuator pompa berjalan karena suhu melebihi batas waktu yang ditentukan dan ini diindikasikan terjadi kebakaran.

\section{Pembahasan Sistem Keseluruhan}

Berdasarkan pengujian secara keseluruhan yang telah dilakukan, diketahui bahwa: sensor suhu, rangkaian penguat, ADC, mikrokontroler, rangkaian LCD, keypad, driver relay buzzer dan pompa berjalan sesuai dengan perancangan. Setiap bagian dalam sistem pada perencanaan ini bekerja sesuai dengan kontrol masing-masing. Hal ini dilakukan dengan merangkai semua blok-blok yang ada menjadi satu sistem. Sistem ini di uji cobakan dengan melihat hasil keluaran yang diperoleh yakni berupa SMS dari HP yang tersambung dengan mikrokontroler dan berjalannya aktuator. Setelah di ujicoba semua perangkat keras berjalan dengan baik dan sesuai dengan perencanaan.

\section{KESIMPULAN}

Dari hasil penelitian dan pembahasan tentang sistem pengendali peringatan dini kebakaran pada ruko melalui SMS dapat disimpulkan bahwa:

1. Alat yang dibuat pada sistem ini dapat bekerja dengan baik, sensor suhu yang digunakan dapat bekerja sesuai dengan setting point yang diberikan. Buzzer akan menyala jika suhu melebihi setting point dan HP akan mengirim SMS kepada pemilik ruko, kemudian bila suhu tetap naik secara otomatis pompa akan menyala.

2. Secara keseluruhan alat komunikasi antara HP dengan mikrokontroler dapat bekerja dan berfungsi sebagaimana yang diharapkan, sehingga diharapkan dapat dimanfaatkan sebagai alat pengendali peringatan dini. Mikrokonktroler AT89S8252 sebagai pengendali utama, cukup efisien karena membutuhkan perangkat keras yang sedikit serta kebutuhan sumber catu daya yang kecil.

\section{DAFTAR PUSTAKA}

Anonimous. Microcontroller AT89S8252. www. atmel.com. pdf diakses tanggal 17-112008

Anonimous. IC LM35.www.national.com.com. Pdf diakses tanggal 17-11-2008

Anonimous. ADC PCF8591.www.philips-semiconductor.com. Pdf diakses tanggal 17-112008

Anonimous. AT Command Set reference manual for Siemens phones.Pdf diakses tanggal 15-11-2008

Clayton george and winder steve.2005. Operational Amplifiers Edisi Kelima. Jakarta: Erlangga

Hasan, fuad. 2004. Alat Pendeteksi Titik Awal Kebakaran Dalam Ruangan Dilengkapi Kamera. Skripsi Tidak Diterbitkan. Malang: Fakultas Teknik Universitas Brawijaya 
Istiyanto Eko Jazi dan Efendy Yeyen. 2004. Rancangan Dan Implementasi Prototipe Sistem Kendali Jarak Jauh Berbasis AT89C52 Dan Layanan SMS GSM. Jurnal ILMU DASAR Vol. 5 No. 2, 2004 :76-86

Malik Ibnu,Moh. 2003. Belajar Mikrokontroler ATMEL AT89S8252. Yogyakarta: Gava Media

Malvino, Albert paul. 1999. Prinsip-prinsip Elektronika Edisi Kedua. Jakarta: Erlangga

Seiko Instrument. 1987. Liquid Crystal Display Module. Japan. Pdf. Diakses tanggal 1911-2008

Sumisjokarto. 1985. Elektronika Praktis Untuk Pemula dan wiraswastawan. Jakarta: PT Multi Media

Widodo, Sigit. 2005. Elektronik Digital dan Mikroprosesor. Yogyakarta: Penerbit Andi. 